Acta Horticulturae et Regiotecturae - Special Issue

Nitra, Slovaca Universitas Agriculturae Nitriae, 2021, pp. 20-26

\title{
IMPACT OF CLIMATE CHANGE ON SOME AGRICULTURAL CROPS DISTRIBUTION AND PRODUCTIVITY IN GEORGIA
}

\author{
Lia MEGRELIDZE ${ }^{1 *}$, Nato KUTALADZE ${ }^{1}$, Gizo GOGICHAISHVILI ${ }^{1}$, Marina SHVANGIRADZE ${ }^{2}$ \\ ${ }^{1}$ National Environmental Agency of Ministry of Environment Protection and Agriculture of Georgia, Tbilisi, Georgia \\ ${ }^{2}$ Sustainable Development Centre - Remission, Tbilisi, Georgia
}

\begin{abstract}
Under the increase of the concern for food security in the world, mainly caused by water resources shortages, the forecast and determination of crop yield at regional scale has been considered as a strategic topic. This study has been conducted to assess the possible impacts of the climate change on cereal crops productivity and irrigation requirement for two main producing regions of Georgia, according to the current crop pattern, and for the 2050s periods. With this aim, water-driven FAO-AquaCrop model has been used. Furthermore, ongoing and forecasted changes, up to the end of the century, in agro-climatic zones relevant for cereals production have been assessed. The climate change data was generated for RCP4.5 scenario through the global circulation model ECHAM4.1, dynamically downscaled on the region via regional climate model (RegCM4.1). Results show overall increase in cereal crop yields, but also enhancement in water shortages even considering optimum management practices under rainfed conditions. Based on the results obtained, recommendations have been developed for adaptation measures to the climate change for the Georgia Agriculture sector.
\end{abstract}

Keywords: climate change, impact modeling, agro-climatic zoning

The Cclimate change already revealed occuring on the territory of Georgia significantly influences on one of the priority sectors of economy - agriculture due to increase in water demand, decrease in harvest productiveness and limitation in water accessibility particularly in those regions, where irrigation is essential or an advantageous necessity (NALAG, 2016). Besides, changes in agro-climatic zones against the background of the temperature increase and changing precipitation patterns is one of the highest risks caused by the climate change for the agriculture sector (Cola et al., 2017). Reduction, growth or shifting of agro-climatic zones requires implementation of significant changes in this sector.

The aim of the paper is to assess the impact of the current and the future climate change on the territorial distribution (agro-climatic zoning) of grain crops (winter wheat, maize), as well as on the crop productivity and irrigation water requirement in the main regions producing these crops (Kakheti, Samegrelo-Zemo Svaneti).

\section{Material and method}

\section{Crop productivity and irrigation water requirement}

For assessment of the climate change impact on the agricultural crop productivity and irrigation water demand it there was selected the quantitative model - Aquacrop, developed by the FAO (Food and Agriculture organization) Land and Water Department (Steduto et al., 2012). The model is already calibrated and validated for the number of crops of worldwide global and local food security importance; it particularly goes well with the conditions, where the water limitation factor is the main determinant in harvest productivity.

The following information should be provided to the Aquacrop model for crop simulation:

- Characteristics of environmental conditions - climate parameters (ETo, temperature, precipitation, $\mathrm{CO}_{2}$ ).

- Agricultural crop type and parameters of (sowing method, phenological phases, canopy cover, root depth, degree of response to various soil stresses).

- Agricultural management - irrigation (method, schedule) and field measures (mulching, soil tillage...).

- Soil profile characteristics: soil type and parameters (physical parameters, soil granulometric composition, organic matter content (humus), number of horizons, water content, pedotransfer functions).

- Groundwater table (depth and salinity).

The model has the ability to change the starting date of the growing season, simulation period, the initial (soil water content and salinity) and off-season (description of irrigation and field management practices carried out outside the growing season) conditions. In addition, in the presence of relevant

Contact address: Lia Megrelidze, National Environmental Agency of Ministry of Environment Protection and Agriculture of Georgia, 150, David Agmashenebeli Ave., 0112, Tbilisi, Georgia; 2 +995 591404 139; e-mail:__megrelidze@hotmail.com 
observational data at different stages of crop development, through model utilization, it is possible to test the validity of the results obtained using known statistical means.

Current climate data (air temperature, atmospheric precipitation, wind speed, relative humidity, water vapour pressure, etc.), as well as agriculture crop (phenological calendar, root depth) and soil parameters was were taken from the database of the Georgian meteorology and agrometeorology observation network.

Reference evapotranspiration was calculated using FAO ETo calculator (Allen et al., 1998).

For simulation of the future climate change, IPCC climate change For simulation of future climate change, IPCC climate change Representative Concentration Pathways (RCPs) scenario 4.5 was used (IPCC, 2014), that is intermediate stabilisation pathway in which radiative forcing is stabilised at approximately $4.5 \mathrm{~W} . \mathrm{m}^{-2}$ after 2100 without ever exceeding that value (the corresponding Extended Concentration Pathways (ECPs) assuming constant concentrations after 2150). Simulated with the Global Change Assessment Model (GCAM), RCP4.5 includes long-term, global emissions of greenhouse gases, short-lived species, and land-use-landcover in a global economic framework..

Climatic parameters were obtained from the Global Circulation Model (ECHAM4.1) dynamically downscaled on the region utilizing the Regional Climate Model (RegCM4.1).

For the assessment of current changes, according to the selected locations for the specific agricultural crops, tendencies of changes of crop yield related parameters (growing season rainfall, reference evapotranspiration, growing degree days, carbon dioxide concentration, Infiltrated water, drained water, surface runoff, soil evaporation, crop transpiration, growing cycle, soil salinity and fertility stress, temperature stress, leaf expansion stress, stomatal stress, total biomass, relative biomass, harvest index, yield, water productivity) and irrigation water requirement were evaluated in the period 1966-2015, also, average indicators of the two 25-year sub-periods were compared (1966-1990 and 1991-2015). With the aim of assessment of future changes, the same indicators for the period 2021-2050 were calculated in accordance with locations and crops and compared with the second reporting period (1991-2015). According to studies (Ahouissoussi et al., 2014a; Ahouissoussi et al., 2014b), the stimulation of plant photosynthesis due to elevated $\mathrm{CO}_{2}$ concentrations, leading led to either enhanced productivity and/or efficiency of primary production. To account the "fertilization" effect of increasing atmospheric $\mathrm{CO}_{2}$ on crop yield, modeling was conducted twice, once with an annually adapted $\mathrm{CO}_{2}$ concentration according to the RCP-4.5 scenario and once with a fixed concentration of $400 \mathrm{ppm}$ to separate the influence of $\mathrm{CO}_{2}$ from that of the other input variables.

Impact of the climate change on winter wheat productivity and water demand was assessed for the Kakheti region based on observations of the Dedoplistskaro meteorological station, and for maize - for the SamegreloZemo Svaneti region based on the Zugdidi meteorological station.

The model simulation was performed at the research territory in correspondence with the widespread main soil types. One modifications of soil parameters of three different soil types (Vertisols, natric Vertisols, black alkalized and natric) in the Dedoplistskaro municipality and one type (plinting and stagnic acri soils) - in the Zugdidi municipality were selected, with regard of to soil horizons depths. These soils with granulometric composition correspond to the types of sandy loam and clay soils in Kakheti and silt loam, loam and sandy loam soils in Samegrelo.

In case of wheat, soil water initial content and salinity were taken as an initial condition: Total Available Water (TAW) for Vertisols were taken as $70 \%$ of Field Capacity (FC), $50 \%$ for Natric Vertisols and 30\% for black alcalized and natric (saline) soils. However, another initial condition was added for the black alcalized and natric soil: soil salinity.

The initial conditions for maize were not considered in the model, as the Total Available Water (TAW) was taken to be equal to Field Capacity (FC).

In order to assess Net Irrigation Requirement and irrigation effect on crop productivity, water deficit was calculated for all soil types according to two scenarios of Readily Available Water (RAW) in the root expansion zone, when the soil water depletion of the root zone is $50 \%$ and $30 \%$ of RAW (RAW50, RAW30) for winter wheat and $50 \%$ and $70 \%$ of RAW (RAW50, RAW70) - for maize.

When simulating maize yield, the presence of groundwater table was also taken into account - on average at a depth of $3 \mathrm{~m}$ and with no salinity.

\section{Agro-climatic zones}

The main factors of agriculture crop productivity are heat and moisture supply conditions. To characterize these conditions, areal changes of the agro-climatic zones of selected crops was were evaluated regarding changes of the following agro-climatic parameters: growing degreedays, growing season rainfall and average of absolute minimum temperature (these are the parameters used for agro-climatic zoning of Georgia for the first time in 1970s (Turmanidze, 1978)).

As in the modeling case, climate data of the period 1966-2015 was were used from the database of the Georgia meteorological observation network and based on these data, favourable areas for the spread of research crops were compared in two 25-years sub-periods (1966-1990 \& 1991-2015). Forecasted changes of agro-climatic zones was were performed for the end of century (2070-2099), as changes in the distribution or shifting of zones are likely to be more apparent in the relatively long run.

The allocation of favourable areas for the cultivation of selected agricultural crops was carried out based on the following agro-climatic parameters:

- in order to produce winter wheat, growing degreedays in the interval $2,100-2,200{ }^{\circ} \mathrm{C}$ and $600 \mathrm{~mm}$ precipitation in total are required. Vegetation period of this crop commences from September, it halts from late November, up to the end of March and further continues development up to the harvesting (late June);

- to produce maize, for the early and late species, growing degree-days required is $1,700-2,800,{ }^{\circ} \mathrm{C}$ and for the averagely ripened maize $-2,200{ }^{\circ} \mathrm{C}$. Required total precipitation for both, early and late species, is $800 \mathrm{~mm}$. Agro-climatic zoning was performed for the averagely ripened maize (Meladze, Meladze, Trapaidze, 2018) 
By this approach, the following three zones were identified as a result of agro-climatic zoning:

1. There areis not enough heat supply to produce wheat/ maize.

2. There are additional water supply requirements to produce wheat/maize.

3. There are favourable climatic conditions to produce wheat/maize.

\section{Results and discussion}

\section{Climate change - current trends and future scenarios}

During the last half-a-century (1966-2015), mean annual air temperature in Georgia has demonstrated solely growing tendency (Keggenhoff, Elizbarashvili, King, 2015; Elizbarashvili et al., 2017). The average increment of temperature between two periods of time (1966-1990 and 1991-2015) at the most parts of the territory made about $0.5^{\circ} \mathrm{C}$, thereto it should be noted that the warming process is the most intense in the municipalities selected for the modeling (Zugdidi, Dedoplistskaro), where the annual temperature increase reaches $0.8-1.0^{\circ} \mathrm{C}$. Warming is taking place in most areas, mainly due to increase in air temperatures in June - October period. The sharpest increase took place in August, varying in the range of $1.2-1.6^{\circ} \mathrm{C}$. In April-May, the change in the average temperature is insignificant and relatively unstable.

According to the projection (UNFCCC, 2015), to 2050s the growth of temperature over the entire territory will be more even and limited in the interval $1.0-1.5^{\circ} \mathrm{C}$. However, at the territory of Samegrelo (Zugdidi), the temperature increment will be smaller and vary between 0.5 and $1.0^{\circ} \mathrm{C}$.

For the period 2070-2099, warming is expected on the whole territory of the country, within $3-4{ }^{\circ} \mathrm{C}$

For the past half-a-century, the variation of annual amount of precipitation has exhibited a mosaic character and the apparent trends did not take place, but there are is noticeable a certain regularity (Elizbarashvili et al., 2014; Elizbarashvili et al., 2016). In particular, the annual rainfall in western Georgia has mainly increased (within 5-15\%), while in some regions of eastern Georgia - reduced. In the annual pattern, changes in seasonal sums of precipitation is are in the range of 15-25\%. Precipitation increase in western Georgia is relatively intense in autumn and in the east - in spring. In the most parts of the territory, especially in Kakheti, reliable negative tendencies in summer precipitation (within 20-25\%) were observed (Meladze, 2017).

According to the projection, by 2050s, precipitation increase is expected to be prevailinged throughout Georgia. Rainfall increase, as in the recent period, is still more intense in western country and precipitation growth tendencies in eastern Georgia is are relatively insignificant (on average 3-5\%).

By 2100 , significant decrease of precipitation is expected on the whole territory with the largest reduction in Samegrelo and Kakheti (20-25\%).

\section{Model validation}

For the main agricultural crops, the crop characteristics have been calibrated by FAO, which are offered in the model as so called default values. The specific crop yield is dependent on the sowing date, on the utilization of fertilizers, pesticides and herbicides and other field management measures and is different from year to year. The influence of this variation was considered during the model validation.

The model was tested for the period 1999-2015 when statistical information on the average yield of wheat and maize in the study regions are available. According to statistical analysis, the acceptable consistency of the simulated harvest compared to the measured one is noted. However, the correlation dependence on a number of factors, such as: amount of precipitation during the growing season, irrigation, soil salinity was find found out.

\section{Modeling results}

Based on the modeling results, Tables 1-3 present the values of winter wheat and maize yield and net irrigation water requirement and its changes between two recent 25-years sub-periods and the 30-years forecast period for investigated sites using the above described input data and initial conditions and according to two scenarios of readily available water (RAW).

\section{Crop productivity}

According to modeling results, average yield of winter wheat in the Dedoplistskaro district during the current period has increased by $10-20 \%$, depending on irrigation and initial conditions. From the three types of soil discussed here (not shown in the tables), yield of winter wheat harvested on Vertisols and Natric Vertisols shows an increase. Exceptions are saline (black alkalized and natric) soils with an area of about $25 \%$ in the municipality (although the share of arable land in such soils does not exceed $5 \%(\approx 2.2$ thousand ha)), where a significant decrease in yield (25-30\%) was revealed. As for maize, according to Table 2, maize yield in the Zugdidi district decreases slightly between the two recent subperiods $(-2 \%)$, although the trend for the whole investigated period (1966-2015) is positive.

According to the projection, it is likely that the trend of yield changes occurred occurring in the current period (1966-2015) will continue until the middle of the century. Growth for winter wheat is significant both in terms of $\mathrm{CO}_{2}$ fertilization or without it, and in rainfed farming in the forecast period it is in the range of $70-100 \%$ compared to the second 25-years period (1991-2015), which corresponds to 4-5 t.ha ${ }^{-1}$, in on average. It should be noted that increase in yield was revealed for all three types of soil. In the case of maize, as in the current period, the changes are insignificant and in the forecast period with regard to the period 1991-2015 are in the range of $\pm 4 \%$, which does not exceed 0.1 t.ha $^{-1}$ on average.

The climate change will decrease the variability of winter wheat from year to year, on maize yield, this impact is again negligible. It could be seen from the crop variation coefficient (CV). In the investigated periods, it varies slightly from 0.1 to 0.3 for maize, and in case of wheat in the two current sub-periods it ranges from 0.6 to 0.8 , but in 20212050 it is twice as small (0.3). Therefore, under the current rainfed farming conditions, less stable wheat yields are expected. The forecast is the most optimal for the forecast period, which implies a higher and more stable harvest of winter wheat. 
Figure 1 shows the exceedance probability curves of simulated crops for the baseline (1966-2015) and forecast (2021-2050) periods for study regions and confirms future changes in crop productivity compared to the baseline period. However, for example, if in the forecast period in Dedoplistskaro once in 100 years (1\% probability) it is probable that the yield will be at least 4 t.ha $^{-1}$, in the current period (1966-2015), crop yield of the same probability (1\%) drops to 0 . The yield of $2 \%$ probability (expected once in 50 years) is 2 t.ha $^{-1}$ in the current period, and increases to 4-5 t.ha ${ }^{-1}$ in the future (2021-2050).

Table 1 Values and changes of growing season climate characteristics and winter wheat productivity between the periods: 1991-2015 (2) vs 1966-1990 (1) and 2021-2050 (3) vs 1991-2015 (2)

\begin{tabular}{|c|c|c|c|c|c|c|c|c|c|c|}
\hline \multirow[t]{3}{*}{ Period } & \multirow{3}{*}{ 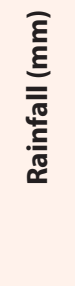 } & \multirow{3}{*}{ 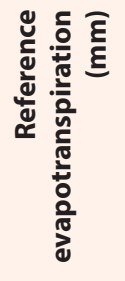 } & \multirow{3}{*}{ 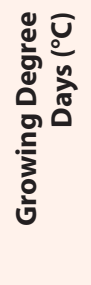 } & \multirow{3}{*}{ 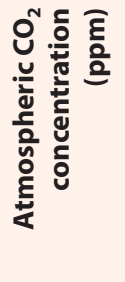 } & \multicolumn{6}{|c|}{ Yield (t.ha ${ }^{-1}$ ) } \\
\hline & & & & & 윤 & 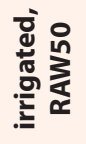 & 흃 & 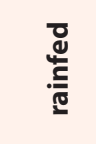 & 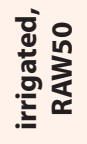 & 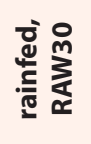 \\
\hline & & & & & \multicolumn{3}{|c|}{ assuming $\mathrm{CO}_{2}$ fertilization } & \multicolumn{3}{|c|}{ assuming no $\mathrm{CO}_{2}$ fertilization } \\
\hline 1966-1990 (1) & 467 & 494 & 2185 & 336 & 2.4 & 6.2 & 6.2 & 2.4 & 6.2 & 6.2 \\
\hline 1991-2015 (2) & 441 & 505 & 2329 & 376 & 2.7 & 7.5 & 7.5 & 2.6 & 7.3 & 7.3 \\
\hline $2021-2050(3)$ & 449 & 385 & 2544 & 449 & 5.4 & 8.5 & 8.3 & 4.6 & 7.5 & 7.3 \\
\hline Abs. change_21 & -25 & 11 & 144 & 40 & 0.2 & 1.2 & 1.2 & 0.2 & 1.1 & 1.1 \\
\hline Abs. change_32 & 8 & -120 & 215 & 73 & 2.7 & 1.0 & 0.9 & 1.9 & 0.2 & 0.0 \\
\hline Rel. change_21 & $-5 \%$ & $2 \%$ & $7 \%$ & $12 \%$ & $9 \%$ & $20 \%$ & $20 \%$ & $7 \%$ & $17 \%$ & $17 \%$ \\
\hline Rel. change_32 & $2 \%$ & $-24 \%$ & $9 \%$ & $19 \%$ & $102 \%$ & $14 \%$ & $12 \%$ & $75 \%$ & $3 \%$ & $0 \%$ \\
\hline
\end{tabular}

Table 2 Values and changes of growing season climate characteristics and winter wheat productivity between the periods: 1991-2015 (2) vs 1966-1990 (1) and 2021-2050 (3) vs 1991-2015(2) (Samegrelo-Zemo svaneti, Zugdidi)

\begin{tabular}{|c|c|c|c|c|c|c|c|}
\hline \multirow[t]{2}{*}{ Period } & \multirow{2}{*}{$\begin{array}{c}\text { Rainfall } \\
\text { (mm) }\end{array}$} & \multirow{2}{*}{$\begin{array}{c}\text { Reference } \\
\text { evapotranspiration } \\
(\mathrm{mm})\end{array}$} & \multirow{2}{*}{$\begin{array}{c}\text { Growing } \\
\text { degree days } \\
\left({ }^{\circ} \mathrm{C}\right)\end{array}$} & \multirow{2}{*}{$\begin{array}{c}\text { Atmospheric } \mathrm{CO}_{2} \\
\text { concentration } \\
\text { (ppm) }\end{array}$} & \multicolumn{3}{|c|}{ Yield $\left(t . h a^{-1}\right)$} \\
\hline & & & & & rainfed & $\begin{array}{c}\text { irrigated, } \\
\text { RAW50 }\end{array}$ & $\begin{array}{r}\text { rainfed } \\
\text { RAW70 }\end{array}$ \\
\hline 1966-1990 (1) & 742 & 470 & 1740 & 336 & 2.03 & 2.10 & 2.09 \\
\hline $1991-2015$ (2) & 677 & 492 & 1891 & 376 & 1.99 & 2.16 & 2.14 \\
\hline $2021-2050(3)$ & 910 & 506 & 1912 & 449 & 1.94 & 2.21 & 2.17 \\
\hline Abs. change_21 & -65 & 22 & 152 & 40 & -0.04 & 0.06 & 0.05 \\
\hline Abs. change_32 & 233 & 14 & 21 & 73 & -0.05 & 0.05 & 0.03 \\
\hline Rel. change_21 & $-9 \%$ & $5 \%$ & $9 \%$ & $12 \%$ & $-2 \%$ & $3 \%$ & $3 \%$ \\
\hline Rel. change_32 & $34 \%$ & $3 \%$ & $1 \%$ & $19 \%$ & $-3 \%$ & $2 \%$ & $1 \%$ \\
\hline
\end{tabular}

Table 3 Values and changes of winter wheat and maize net irrigation requirements between the periods: 1991-2015 (2) vs 1966-1990 (1) and 2021-2050 (3) vs 1991-2015 (2). RAW30, RAW50, RAW70 refers to readily available water in the root expansion zone, when the soil water depletion of the root zone is $30 \%, 50 \%$, $70 \%$, respectively

\begin{tabular}{|c|c|c|c|c|}
\hline \multirow[t]{2}{*}{ Period } & \multicolumn{2}{|c|}{ Kaheti, Dedoplistskaro } & \multicolumn{2}{|c|}{ Samegrelo-Zemo Svaneti, Zugdidi } \\
\hline & RAW50 & RAW30 & RAW50 & RAW70 \\
\hline $1966-1990(1)$ & 126 & 140 & 17 & 6 \\
\hline $1991-2015$ (2) & 154 & 168 & 30 & 16 \\
\hline $2021-2050(3)$ & 60 & 73 & 41 & 18 \\
\hline Abs. change_21 & 28 & 28 & 14 & 9 \\
\hline Abs. change_32 & -93 & -95 & 11 & 2 \\
\hline Rel. change_21 & $22 \%$ & $20 \%$ & $82 \%$ & $148 \%$ \\
\hline Rel.change_32 & $-61 \%$ & $-57 \%$ & $37 \%$ & $14 \%$ \\
\hline
\end{tabular}




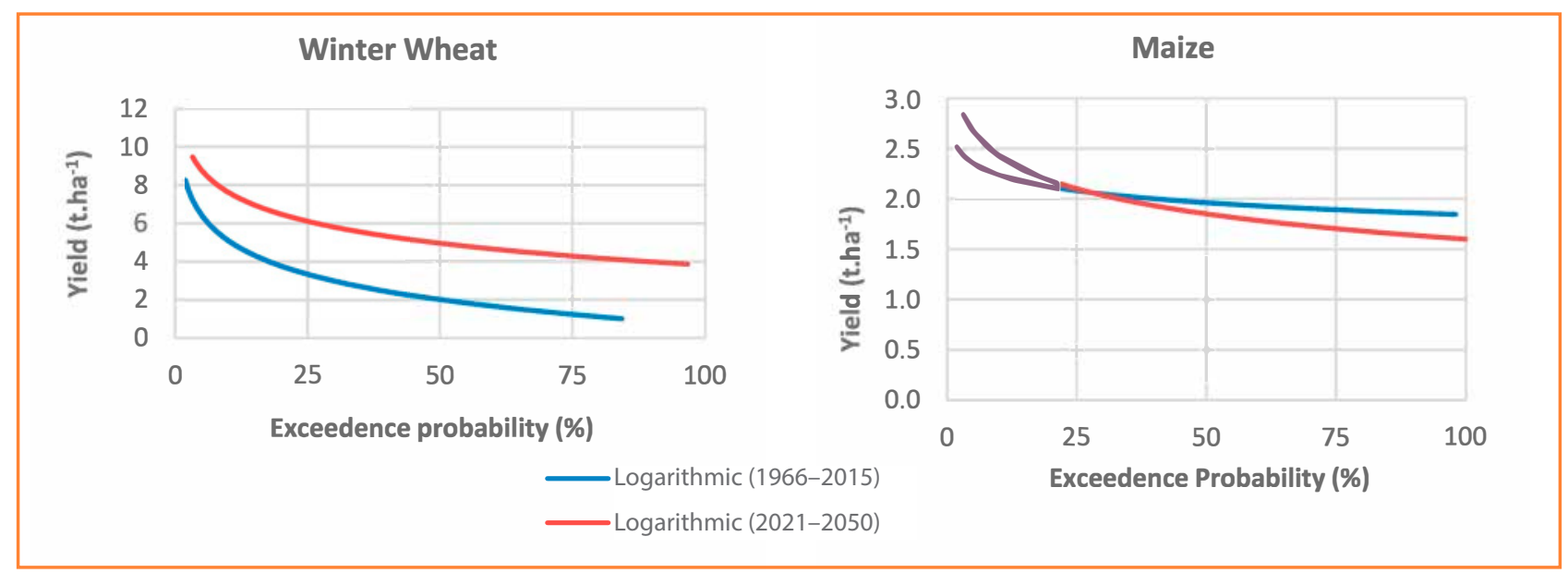

Figure 1 Exceedance probability (\%) of wheat and maize yields for the recent and forecast periods

\section{Irrigation water requirement}

During the recent period, the study area has shown a tendency to increase the water shortage of grain crops, which is obvious against the background of declining rainfall during the growing season (Table 3 ). The demand for winter wheat irrigation water between the two recent subperiods has increased by $20-25 \%$, while that of maize - by about 2-2.5 times. However, as the water deficit for maize is negligible, the quantitative increase is only $10-30 \mathrm{~mm}$.

Against the background of climate change, according to both scenarios of soil waterlogging in the future, to maintain maximum yields of winter wheat, in the forecast period compared to the current situation, whilst maintaining almost the same amount of precipitation in the growing season, irrigation water demand decreases by $55-60 \%$, which should be due to a significant reduction in evapotranspiration (-24\%). The irrigation demand for maize is growing $(40 \%-60 \%)$, but quantitatively remains insignificant in the future and does not exceed $20-50 \mathrm{~mm}$. In other words, it can be said that the problem of water shortage for maize in the study area is not revealed and according to the modeling results, such a problem is not expected with in athe future scenario.

To ensure maximum yield of winter wheat, the largest amount of water is still needed for sown areas on saline soils, and the least water will be lacking in Vertisols, where the average irrigation demand during the recent period (1966-2015) is $100-150 \mathrm{~mm}$, and in the future decreases to $50-100 \mathrm{~mm}$ (not shown in the tables). About 5-15\% more water is needed on Natric Vertisols, and 30-60\% more on saline soils, which is currently $150-200 \mathrm{~mm}$, and in the future it will be in the range of $80-120 \mathrm{~mm}$. However, it should be noted that these are averaged indicators, and future climate change scenarios suggest an increase in the probability of certain dry, hot years, with severe droughts, which will significantly increase the irrigation water demand of any area during such periods.

The results also indicate that under proper irrigation it is possible to significantly increase the average yield of wheat. In particular, as a result of sufficient irrigation in the study region, winter wheat yields may increase by $2-3$ times. During the recent period, such an increase will result in an average yield of 6-8 tha ${ }^{-1}$, and by the middle of the century the yield will reach 9 t.ha $^{-1}$. Growth of yields are approximately equal between rainfed and irrigated farming conditions in the whole investigated period. Irrigation will have relatively less effect in the forecast period when the plant's water deficit is the smallest. As for maize irrigation, modeling confirms that due to the high moisture content of study area, use of irrigation will not have any significant impact on crop yield and as a result of irrigation, increase in maize productivity will not exceed $10-15 \%$, which is in averages $2-2.5 \mathrm{t}^{-h a^{-1}}$ for both rainfed and irrigated agriculture in the forecast period.

Changes in water demand for considered agricultural crops have been assessed under the constant fertility level and other boundary conditions.

It is important to mention that irrigation technology will also have an effect on water demand, which will be used on certain location, due to the fact that different irrigation systems are characterized by different levels of water provision effectiveness. The model relies on the so-called sprinkler irrigation technology for net irrigation requirement calculation.

\section{Ongoing and forecasted changes in agro-climatic zones relevant for cereals production}

Figures 2 and 3 show the zoning of Georgia territory according to the investigated periods (1966-1990, 19912015, 2070-2099) for winter wheat and corn, and in the Table 4 the areas of zones where cultivation of these crops is favourable is are presented.

Areas of the zones favourable for growing of winter wheat where this crop can be grown in rainfed conditions are currently increased by about $5 \%$ and will increase by up to $40 \%$ in the future and this will occur basically due to temperature growth, when growing degree-days achieve $2,100-2,200{ }^{\circ} \mathrm{C}$ at $1,200-1,500 \mathrm{~m}$ altitudes above sea level. This is the medium-sized mountainous zone distinguished with complex orography, extensively fragmented and represented with small land plots. The soil is favourable for wheat growing. The most part of the territory is currently covered with the forests and pastures.

According to Figure 3 and Table 4, in the recent period (1966-2015), the areas favourable for maize growing 

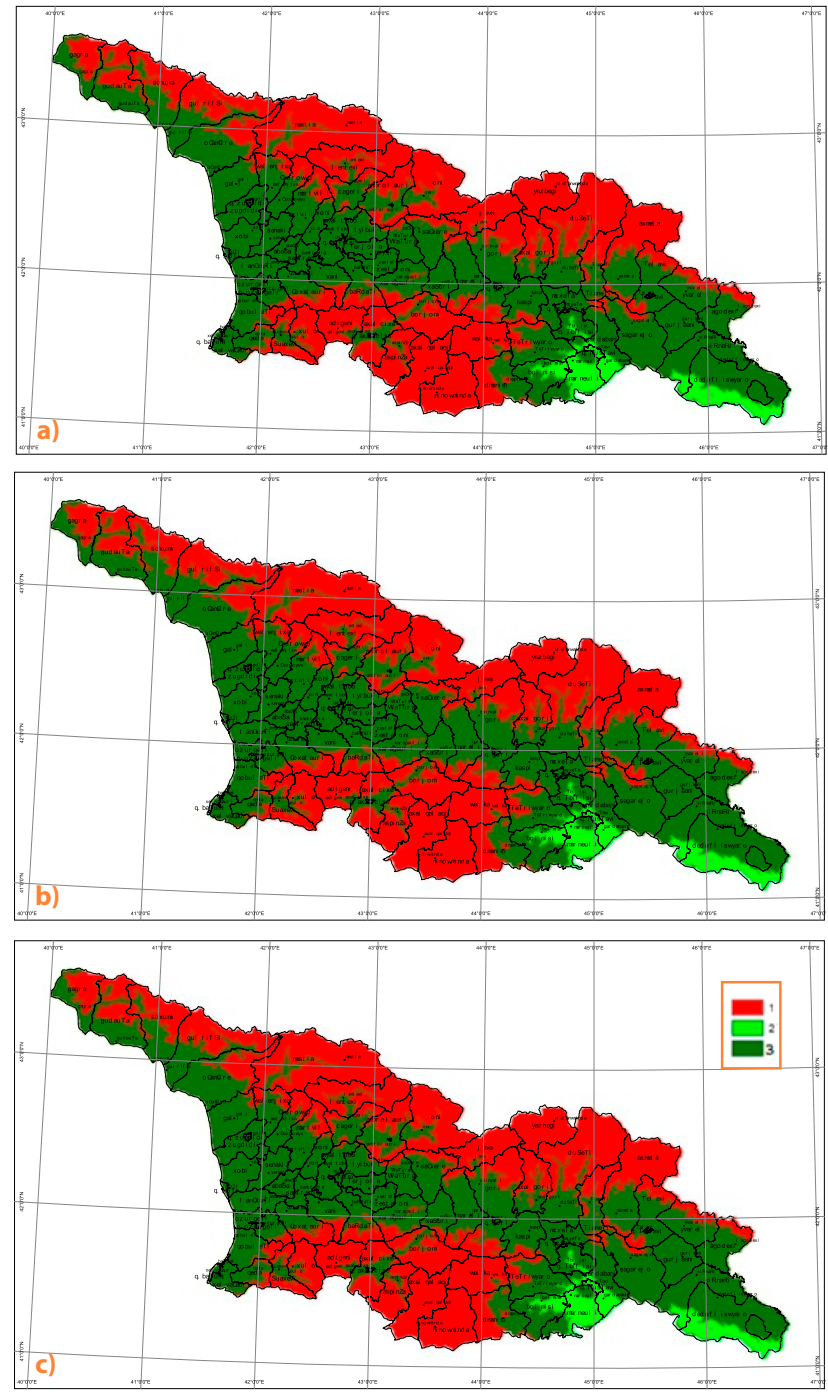

Figure 2 Changes in wheat agro-climatic zoning: a) 19661990, b) 1991-2015 and c) 2070-2099

1 - zone with insufficient heat supply to produce crop; 2 - zone require additional water supply; 3 - zone with favourable climate conditions

are increasing. In the future, suitable areas will increase significantly in case of irrigated crops while the areas with rainfed farming will reduce. Part of the territories warm enough to grow maize is mostly the highlands where, supposedly, the precipitation will be sufficient for maize growing without irrigation. Thus, in these areas, maize growing might be more reasonable in economic respect.

Although, it should be noted that even in the current period, the sown areas of wheat and maize are much smaller

Table 4 Areas of the zones (ha) favourable for wheat and maize growing in different periods

\begin{tabular}{|l||c|c|c|c|}
\hline Crop & Period & $\mathbf{1 9 6 6 - 1 9 9 0}$ & $\mathbf{1 9 9 1 - 2 0 1 5}$ & $\mathbf{2 0 7 0 - 2 0 9 9}$ \\
\hline \hline \multirow{2}{*}{ Wheat } & Zone 2 & 844,200 & 846,900 & 954,600 \\
\cline { 2 - 5 } & Zone 3 & $3,171,800$ & $3,365,300$ & $4,675,600$ \\
\hline \multirow{2}{*}{ Maize } & Zone 2 & $1,601,500$ & $1,643,400$ & $3,528,000$ \\
\cline { 2 - 5 } & Zone 3 & $2,414,600$ & $2,568,800$ & $1,742,200$ \\
\hline
\end{tabular}
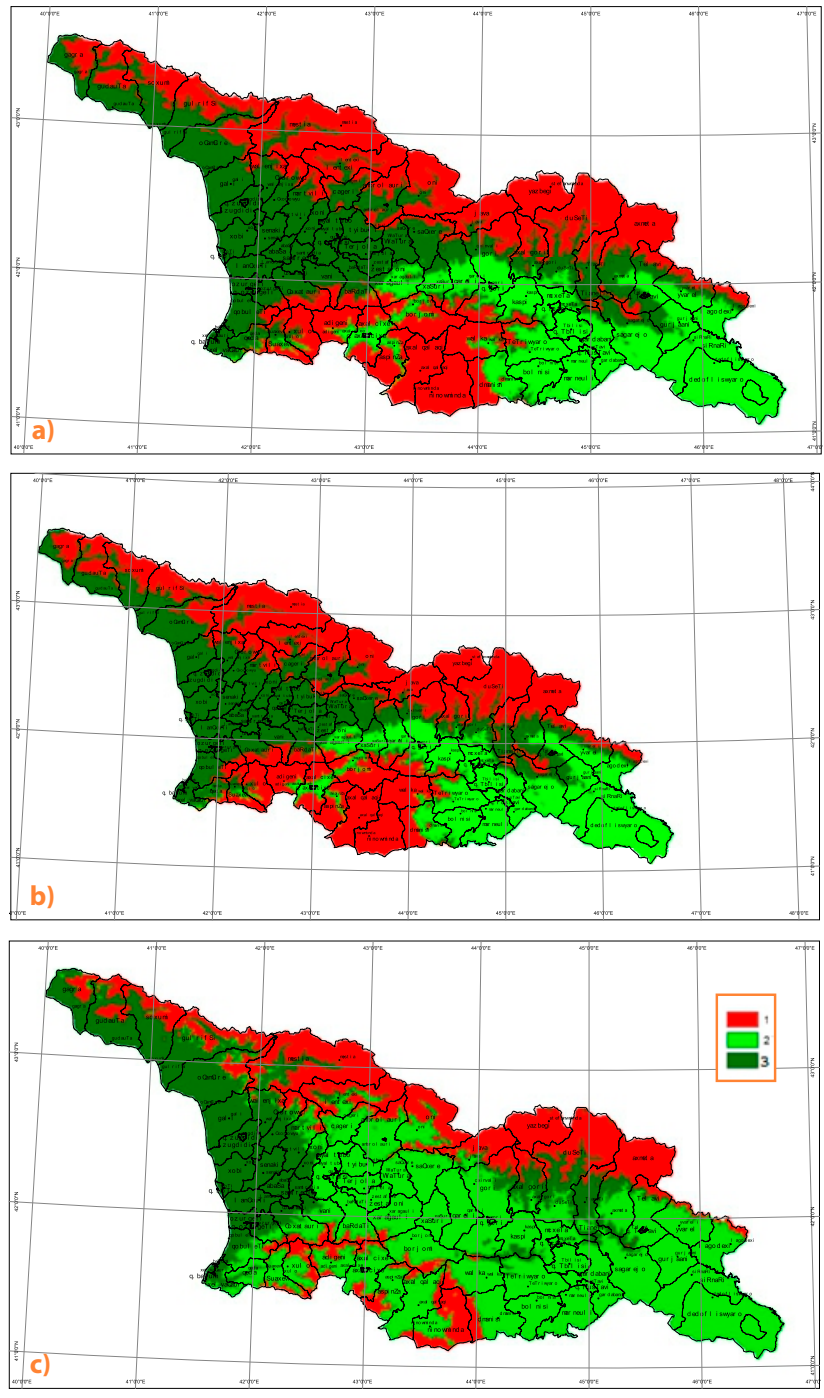

Figure 3 Changes in maize agro-climatic zoning: a) 19661990, b) 1991-2015 and c) 2070-2099

1 - zone with insufficient heat supply to produce crop; 2 zone require additional water supply; 3 - zone with favourable climate conditions

compared to the area with favourable climatic conditions for growing these cereals. This is due to the advantage of other economically more profitable crops, historical-cultural or other circumstances.

\section{Conclusions}

According to the climate change selected scenario (that stabilizes radiative forcing at $4.5 \mathrm{~W} \cdot \mathrm{m}^{-2}$ in the year 2100), potential yield of winter wheat will grow, both with and without irrigation. Irrigation effect is particularly significant for the cultivated areas on saline (black alkalized and natric) soils in the recent time while in the prognosis period the effect is relatively lower. Whilst the climate change has smaller effect on maize productivity, in particular: potential yields of the maize will remain quite stable from year to year, both for rainfed and irrigated agriculture and changes between the investigated periods is are insignificant $(+4 \%)$, amounting, in average, to 2-2.5 t.ha ${ }^{-1}$. Also, by the end of the century, the areas favourable for growing cereals will increase significantly. 
For winter wheat cultivation by about $40 \%$ will extend zones with suitable climate conditions will extend by about $40 \%$, but for maize, growth is expected to increase by almost 2 times areas requiring additional water supply.

Irrigation effect is particularly significant for winter wheat cultivated on saline (black alkalized and natric) soils in the current period while in the prognosis period the effect is relatively lower.

For winter wheat that belongs to the crops moderately sensitive to soil water stress, effect of precipitation reduction is apparent only for the plantations on saline (black alkalized and natric) soils. On the rest of territory, water deficiency caused by reduction of precipitation is compensated by reduction of evapotranspiration and improvement of crop water productivity. According to the future projection, this trend will be maintained at least up to the middle of the century and in the Dedoplistskaro district, even in case of rainfed cultivation, growth of the yields could be expected. Hence, during prognosis period, to maintain maximal yields, water requirement will be $40-60 \%$ lower, compared with the current period. At the same time, it should be considered that by the end of the century, against the background of a significant decrease in precipitation overall country territory would increase areas, where additional water will be needed to grow cereals.

For the maize that belongs to the crops sensitive to soil water stress, effect of precipitation reduction was not apparent due to high moisture content in the studied territory. Due to this, no any significant effect of irrigation on yields was identified.

Increases in air temperature and $\mathrm{CO}_{2}$ are considered as being one of the main components of changing climate, thatclimate that would have significant impact on agriculture crop productivity by the means of increased crop water effectiveness and through the biomass production. The modeling results indicate that the increased concentration of the $\mathrm{CO}_{2}$ will have a positive effect on biomass production of winter wheat, however, $\mathrm{CO}_{2}$ fertilization effect in some cases overlaps with the unfavourable changes of climatic parameters during growing season and is specific depending on the soil type common in the study area. For maize, the above effect and yield increase are relatively small, which is explained by the high ability of carbon fixation by maize.

By default, the AquaCrop model discusses agro-technical measures taken against agricultural crops (such as pest and disease control, weed control, etc.) at the optimal level, which is largely inconsistent with the real situation. Such influences are involved in the model through soil fertility stress. Such stress was not taken into account when simulating the model, as accurate information about the above measures was not available. Thus, the real decline in wheat yields should not only be due to changes in climatic conditions and is likely to be the result of improper exploitation of land and agro-technical measures and inconsistent management. As for maize, it seems that in the studied region, conditions favourable for maize growing exist now, will exist in the future and low average yields (compared with the global figures) are supposedly caused by the crop varieties or some other reasons (vermin, diseases, ineffective management).

One should also bear in mind that nor neither model not nor agro-climatic zoning approach does do not take into consideration impact of such significant factors as extreme phenomena, like floods, hail, strong winds etc. on agricultural crop spatial distribution and productivity. In addition, raised temperature and more frequent heat waves results in increase of the fire risks, vermin propagation and frequency of diseases.

\section{Acknowledgements}

The research was carried out in the frames of the project "Agriculture Modernization, Market Access and Flexibility" (AMMAR) implemented by the Ministry of Environmental Protection and Agriculture of Georgia with IFAD/GEF support, while the development a national adaptation plan for the agricultural sector of Georgia.

\section{References}

Ahouissoussi, N., Neumann J. E., Srivastava, J. P., Okan, C., Droogers, P. (2014a). Reducing the vulnerability of Georgia's agricultural systems to climate change. World Bank. https://doi. org/10.1596/978-1-4648-0148-8

Ahouissoussi, N., Neumann, J. E., Srivastava, J. P. (2014b). Building resilience to climate change in south caucasus agriculture. World Bank. http://dx.doi.org/10.1596/978-1-4648-0214-0

Allen, R. G., Pereira, L. S., Raes, D., Smith, M. (1998). Crop evapotranspiration: guidelines for computing crop water requirements. FAO. http://www.fao.org/3/X0490E/X0490E00.htm.

Cola, G., Failla, O., Maghradze, D., Megrelidze, L., Mariani, L. (2017). Grapevine Phenology and Climate Change in Georgia. International Journal of Biometeorology, (61), 761-773.

Elizbarashvili, E., Kutaladze, N., Keggenhoff, I., Elizbarashvili, M. Kikvadze, B., Gogia, N. (2014). Climate Indices for the Moistening Regimen in the Territory of Georgia amidst Global Warming. European Researcher, (66), 102-107.

Elizbarashvili, E., Elizbarashvili, M., Kutaladze, N., Keggenhoff, I. Elizbarashvili, Sh, Kikvadze, B., Gogia, N. (2016). Spatiotemporal Variations in Climate Moisture Indices in Georgia under Global Warming. Russian Meteorology and Hydrology, (41), 261-267.

Elizbarashvili, M., Elizbarashvili, E., Tatishvili, M., Elizbarashvili, Sh., Meskhia, R., Kutaladze, N., King, L., Keggenhoff, I., Khardziani, T. (2017). Georgian climate change under global warming conditions. Annals of Agrarian Science, (15), 17-25.

Keggenhoff, I., Elizbarashvili, M., King, L. (2015). Recent changes in Georgia's temperature means and extremes: Annual and seasonal trends between 1961 and 2010. Weather and Climate Extremes, (8), 34-45.

IPCC (2014). AR5 Climate change 2014: impacts, adaptation, and vulnerability. IPCC. https://www.ipcc.ch/report/ar5/wg2/

Meladze, M. (2017). Climate change: A trend of increasingly frequent droughts in Kakheti Region (East Georgia). Annals of Agrarian Science, (15), 96-102.

Meladze, M., Meladze, G., Trapaidze, V. (2018). Evaluation of the AgroEcological Potential of Racha-Lechkhumi-Kvemo Svaneti region (Georgia) and Zoning of Crops. SGEM, Ecology and Environment Protection, (18), 361-367.

NALAG (2016). The Georgian Road Map on Climate Change Adaptation. USAID. http://nala.ge/climatechange/uploads/RoadMap/ TheRoadMapEngPre-design reference191_Final.pdf

Steduto, P, Hsiao, T. C., Fereres, E., Raes, D. (2012). Crop yield response to water. FAO. http://www.fao.org/3/i2800e/i2800e.pdf

Turmanidze, T. (1978). Agroklimaticheskie Resursi Gruzinskoi SSR. Leningrad: Gidrometeoizdat.

UNFCCC (2015). Georgia's Third National Communication to the UNFCCC. GEF. https://unfccc.int/resource/docs/natc/geonc3.pdf 